\title{
Spontaneously hypertensive rats are sensitive to thoracic aorta damage induced by a hot and humid environment
}

\author{
TAO XU ${ }^{1 *}$, FADONG LIU $^{1 *}$, YAN LUO ${ }^{1}$, LINGQIN ZHU ${ }^{2}$, JIANGUO NIU $^{3}$ and GUANGHUA LI ${ }^{1-3}$ \\ ${ }^{1}$ Institute of Basic Medical Science; ${ }^{2}$ School of Public Health and Management; \\ ${ }^{3}$ Ningxia Key Laboratory of Cerebrocranial Diseases, Ningxia Medical University, Yinchuan, \\ Ningxia 750004, P.R. China
}

Received May 22, 2016; Accepted May 16, 2017

DOI: $10.3892 /$ etm.2017.5050

\begin{abstract}
The purpose of this study was to investigate the effect of a hot and humid environment on thoracic aorta damage in spontaneously hypertensive rats (SHRs). Wistar-Kyoto (WKY) rats were randomly divided into three groups $(n=8$ in each group): Control group (WKY-CN), heat exposure for $8 \mathrm{~h}$ group (WKY-8) and heat exposure for $24 \mathrm{~h}$ group (WKY-24). The $\mathrm{CN}$ group was exposed to room temperature $\left(24^{\circ} \mathrm{C}\right)$; WKY-8 and WKY-24 group were exposed to heat $\left(32^{\circ} \mathrm{C}\right)$ and $65 \%$ relative humidity for 8 and $24 \mathrm{~h}$, respectively. Accordingly, SHRs were randomly divided into three groups ( $\mathrm{n}=8$ each group): SHR-CN, SHR-8 and SHR-24. After 7 days of heat exposure, the weight, food consumption and blood pressure of rats was measured. Noradrenaline (NA)-induced contraction of aorta rings was measured using an organ bath system, and vascular morphology was observed. Expression levels of apoptotic genes and proteins in the thoracic aorta were also measured. The experimental results indicated that, in the heat exposure environment, rat food intake was reduced. Rat weight was significantly increased in all groups except SHR-24 (all $\mathrm{P}<0.01$ except SHR-8, $\mathrm{P}<0.05)$. Heat exposure significantly increased the blood pressure of rats in the WKY-24 ( $\mathrm{P}<0.01$ for systolic; $\mathrm{P}<0.05$ for diastolic), SHR-8 and SHR-24 (all $\mathrm{P}<0.01$ ) groups. This effect was more notable in SHR compared with WKY. NA-induced contraction of aorta rings significantly increased in the SHR-CN group, compared with the WKY-CN group $(\mathrm{P}<0.01)$. Heat exposure significantly elevated the NA-induced contraction in both $8 \mathrm{~h}$ groups compared with the $\mathrm{CN}$ groups $(\mathrm{P}<0.01)$. This effect was accompanied by structural damage to the thoracic aorta and increased expression of apoptotic genes and proteins. In conclusion, thoracic aorta damages in
\end{abstract}

Correspondence to: Professor Guanghua Li, Institute of Basic Medical Science, Ningxia Medical University, 1160 Sheng-Li Street, Yinchuan, Ningxia 750004, P.R. China

E-mail: ghlee0404@163.com

"Contributed equally

Key words: hot temperature, thoracic aorta, apoptosis
SHRs were more sensitive to heat exposure. The enhanced NA-induced contraction may have partly been due to increased apoptosis in the thoracic aorta.

\section{Introduction}

Higher temperature and high humidity weather is common in the summer, and cardiovascular disease is associated with this environment $(1,2)$. A hot and humid environment is a type of thermal stress on the body (3), however, the effect of a thermal environment on patients with high blood pressure remains unknown. Therefore, investigating the pathophysiological effects of a high temperature and high humidity environment on the body's cardiovascular system may be important in improving the control and prevention of this type of disease.

Previous findings have revealed that thermal stress induces apoptosis and causes vascular damage (4-6). Caspase-3 is thought to be a key apoptosis indicator, its activation indicates an irreversible stage of apoptosis (7). In the regulation of apoptosis, members of the B-cell lymphoma 2 (Bcl-2) family serve key functions (8). The Bcl-2 family can be divided into two categories: One category is anti-apoptotic, and includes Bcl-2, Bcl-xL, Bcl-2-like protein 2 (Bcl-2-L-2), Bcl-2-L-3 and cell death protein 9; The other category of $\mathrm{Bcl}-2$ proteins promotes cell death, and includes Bcl-2-L-4 (Bax), Bcl-2-L-7, Bcl-xS, Bcl-2-L-8, Bcl-2-interacting killer and $\mathrm{BH} 3$-interacting domain death agonist (9). Increased Bax promotes cell apoptosis, whereas increased Bcl-2 inhibits cell apoptosis (10).

Besides apoptosis, vasoreactivity is the most basic and direct indicator that reflects artery vascular function in the body (11). Enhanced contractive function is the primary symptom of a damaged blood vessel $(12,13)$. Increased vasoreactivity is a key mechanism for the development of cardiovascular disease and is a prognostic indicator of arterial health (14). Vasoreactivity of blood vessels is increased by heat exposure (15), however, to the best of our knowledge, this effect has not been investigated in a hypertensive state. The aim of the current study was to investigate the effect of a thermal environment on rats with hypertensive blood pressure. Apoptosis and vasoreactivity of blood vessels was measured and changes in vascular morphology were recorded. 


\section{Materials and methods}

Animals. A total of 24 male Wistar-Kyoto (WKY) rats and 24 male spontaneously hypertensive rats (SHRs) (all 7 weeks old) were provided by the Charles River Laboratories (Wilmington, MA, USA). According to the experimental schedule, WKY rats were randomly divided into three groups (n=8/group): Control group (WKY-CN), heat exposure for $8 \mathrm{~h}$ group (WKY-8) and heat exposure for $24 \mathrm{~h}$ group (WKY-24). SHR rats were randomly divided into three groups (n=8/group): SHR-CN, SHR-8 and SHR-24. The WKY-CN and SHR-CN groups were maintained at room temperature of $24^{\circ} \mathrm{C}$ with $55 \%$ relative humidity, both the WKY- 8 and WKY-24 groups were exposed to a high temperature of $32^{\circ} \mathrm{C}$ at $65 \%$ relative humidity. Heat exposure was performed in an artificial climate chamber (Qianjiang Instrument \& Equipment Co., Ltd., Hangzhou, China). Rats in the WKY-8 and SHR-8 group received a fixed $8 \mathrm{~h}$ (9:00 a.m. to 5:00 p.m.) heat exposure process each day, but were kept in the control conditions $\left(24^{\circ} \mathrm{C}\right.$, $55 \%$ humidity) when they weren't being exposed to heat; the WKY-24 group was exposed to the hot environment all day. The SHR-8 and SHR-24 groups were received the same heat exposure. Food and water were supplied ad libitum. Rats were housed in a 12-h light/dark cycle (light 6:00 p.m. to 6:00 a.m.). Heat exposure lasted for 7 days. The experimental procedures of the present study were approved by the Animal Ethics and Use Committees of Ningxia Medical University (Yinchuan, China), in accordance with the guidelines of the Council of the Physiological Society of China. The behavior and active state of rats were be monitored carefully.

Weight and food consumption. Upon initiation of the heat exposure experiment, the body weights of the rats were measured. During the experiment, food consumption was recorded in each group daily. At the end of the experiment, body weight was measured again.

Blood pressure. Prior to the experiment, systolic and diastolic blood pressure were measured from the rat tails using a blood pressure monitor (BP-2010A; Softron Biotechnology, Beijing, China), and the data were obtained directly from the machine. At the end of the experiment, blood pressure was measured again from the rat tails.

Vasoreactivity. Following anesthesia, the rat chests were immediately opened, and the thoracic aorta was removed and placed into a paraffin platter filled with normal saline. Connective tissue was cut off carefully; the vascular ring (4-5 mm wide) was obtained by sectioning the thoracic aorta. Another section $(5 \mathrm{~mm})$ of the thoracic aorta was harvested for hematoxylin and eosin (H\&E) staining. The rest of the thoracic aorta was submerged in liquid nitrogen and stored at $-80^{\circ} \mathrm{C}$ for subsequent reverse transcription-quantitative polymerase chain reaction (RT-qPCR) and western blotting analyses. The vascular ring was suspended in an organ bath (DMT GmbH \& Co., KG, Essen, Germany) containing $10 \mathrm{ml} \mathrm{Krebs} \mathrm{solution} \mathrm{[ingredients} \mathrm{(all} \mathrm{mmol/l):} \mathrm{Glucose} \mathrm{5.6,}$ $\mathrm{NaCl} 10, \mathrm{NaHCO}_{3} 24.8, \mathrm{KCl} 4.6, \mathrm{CaCl}_{2} 2.5, \mathrm{MgSO}_{4} 1.2$, and $\mathrm{KH}_{2} \mathrm{PO} 4$ 1.2]. The system was ventilated with mixed gas of $95 \% \mathrm{O}_{2}$ and $5 \% \mathrm{CO}_{2}$ continuously, and a constant temperature of $37^{\circ} \mathrm{C}$ was maintained. Resting tension was adjusted to $1 \mathrm{~g}$, and the ring was balanced for $40 \mathrm{~min}$, with Krebs solution replenished every $15 \mathrm{~min}$. Maximal contraction was established by the addition of $60 \mathrm{mM} \mathrm{KCl}$. After resting tension was stable, Krebs fluid was replaced and basal tension was returned to $1 \mathrm{~g}$. A cumulative concentration of noradrenaline (Shanghai Harvest Pharmaceutical Co., Ltd., Shanghai, China) $\left(10^{-10}-10^{-5} \mathrm{M}\right)$ was added to the bath system, and contractive tension was recorded. The vascular tension induced by NA $\left(10^{-10}-10^{-5} \mathrm{M}\right)$ was expressed as a percentage of the maximal contraction tension range induced by $\mathrm{KCl}(60 \mathrm{mM})$.

Morphological observation. A short part $(5 \mathrm{~mm})$ of the thoracic aorta was fixed in $10 \%$ formalin for $12 \mathrm{~h}$ at $4^{\circ} \mathrm{C}$, embedded in paraffin and sliced into tissue sections $(10 \mu \mathrm{m})$. Morphological changes of the thoracic aorta were observed by HE staining (hematoxylin staining for $2 \mathrm{~min}$ at $24^{\circ} \mathrm{C}$; and eosin staining for 5 min at $24^{\circ} \mathrm{C}$ ) using an Olympus DP71 microscope (Olympus Corporation, Tokyo, Japan).

RT-qPCR analysis of caspase-3, Bcl-2 and Bax mRNA expression. Total RNA was extracted from the thoracic aorta using TRIzol reagent (Invitrogen; Thermo Fisher Scientific, Inc., Waltham, MA, USA), according to the manufacturer's protocol. Complementary DNA (cDNA) was synthesized with a First-Strand cDNA Synthesis kit (Thermo Fisher Scientific, Inc.). qPCR was carried out using a Maxima SYBR-Green PCR kit (Thermo Fisher Scientific, Inc.) with primers as listed in Table I. Following an initial $10 \mathrm{~min}$ at $95^{\circ} \mathrm{C}$, the PCR thermal cycling program was performed as follows: $95^{\circ} \mathrm{C}$ for $15 \mathrm{sec}, 60^{\circ} \mathrm{C}$ for $30 \mathrm{sec}$, and extension at $72^{\circ} \mathrm{C}$ for $30 \mathrm{sec}$, for 40 cycles. At the end of the reaction, melting curve analysis was performed to ensure the specificity of the reaction. Relative gene expression levels were determined using the $2^{-\Delta \Delta \mathrm{Cq}}$ method $(11,12)$. $\beta$-actin was used as an internal control.

Protein expression levels of caspase-3, Bcl-2 and Bax. Protein was extracted from the thoracic aorta using a Total Protein Extraction kit for western blotting (KeyGen Biotech Co., Ltd., Nanjing, China). The protein determination was completed using the BCA method (KeyGen Biotech Co., Ltd.). Protein lysates $(100 \mu \mathrm{g})$ were separated by $12 \%$ SDS-PAGE (KeyGen Biotech Co., Ltd.) run for $30 \mathrm{~min}$ at $80 \mathrm{~V}$ and $60 \mathrm{~min}$ at $120 \mathrm{~V}$, followed by transferral to polyvinylidene fluoride membranes (EMD Millipore, Billerica, MA, USA). Following blocking with non-fat milk powder for $1 \mathrm{~h}$ at $24^{\circ} \mathrm{C}$, the membranes were incubated with primary antibodies for $2 \mathrm{~h}$ at $24^{\circ} \mathrm{C}$. Primary antibodies used in the present study were as follows: Rabbit monoclonal anti-Bax (1:5,000; cat no. ab32503), rabbit monoclonal anti-Bcl-2 (1:2,000; cat no. ab136285), rabbit monoclonal anti-Caspase-3 (1:500; cat no. ab4051) and rabbit monoclonal anti- $\beta$-actin $(1: 1,000$; cat no. 5632-1) (all from Abcam, Cambridge, UK). Following washing with TBST three times for $5 \mathrm{~min}$, the membrane was incubated for $2 \mathrm{~h}$ at $24^{\circ} \mathrm{C}$ with secondary antibody horseradish peroxidase-conjugated goat anti-rabbit $\operatorname{IgG}(1: 2,000$; ZB-2301; ZSGB-Bio, Beijing, China). Membranes were subjected to an enhanced chemiluminescence kit (Thermo Fisher Scientific, Inc.). Western blot analysis was performed 
Table I. Sequences of the oligo nucleotide primers used for reverse transcription-quantitative polymerase chain reaction analysis.

\begin{tabular}{|c|c|c|c|c|}
\hline Gene & Direction & Sequence $\left(5^{\prime}-3^{\prime}\right)$ & $\mathrm{Bp}$ & GenBank no. \\
\hline Caspase-3 & $\begin{array}{l}\text { Forward } \\
\text { Reverse }\end{array}$ & $\begin{array}{l}\text { AGCTGGACTGCGGTATTGAG } \\
\text { GGGTGCGGTAGAGTAAGCAT }\end{array}$ & 104 & NM_012922 \\
\hline $\mathrm{Bcl}-2$ & $\begin{array}{l}\text { Forward } \\
\text { Reverse }\end{array}$ & $\begin{array}{l}\text { AGCCTGAGAGCAACCGAAC } \\
\text { AGCGACGAGAGAAGTCATCC }\end{array}$ & 159 & NM_016993 \\
\hline Bax & $\begin{array}{l}\text { Forward } \\
\text { Reverse }\end{array}$ & $\begin{array}{l}\text { TTGCTACAGGGTTTCATCCAG } \\
\text { TGTTGTTGTCCAGTTCATCG }\end{array}$ & 145 & NM_017059 \\
\hline$\beta$-actin & $\begin{array}{l}\text { Forward } \\
\text { Reverse }\end{array}$ & $\begin{array}{l}\text { CACCCGCGAGTACAACCTTC } \\
\text { CCCATACCCACCATCACACC }\end{array}$ & 207 & NM_031144 \\
\hline
\end{tabular}

Bcl-2, B-cell lymphoma 2; Bax, Bcl-2-like protein 4; bp, base pair.
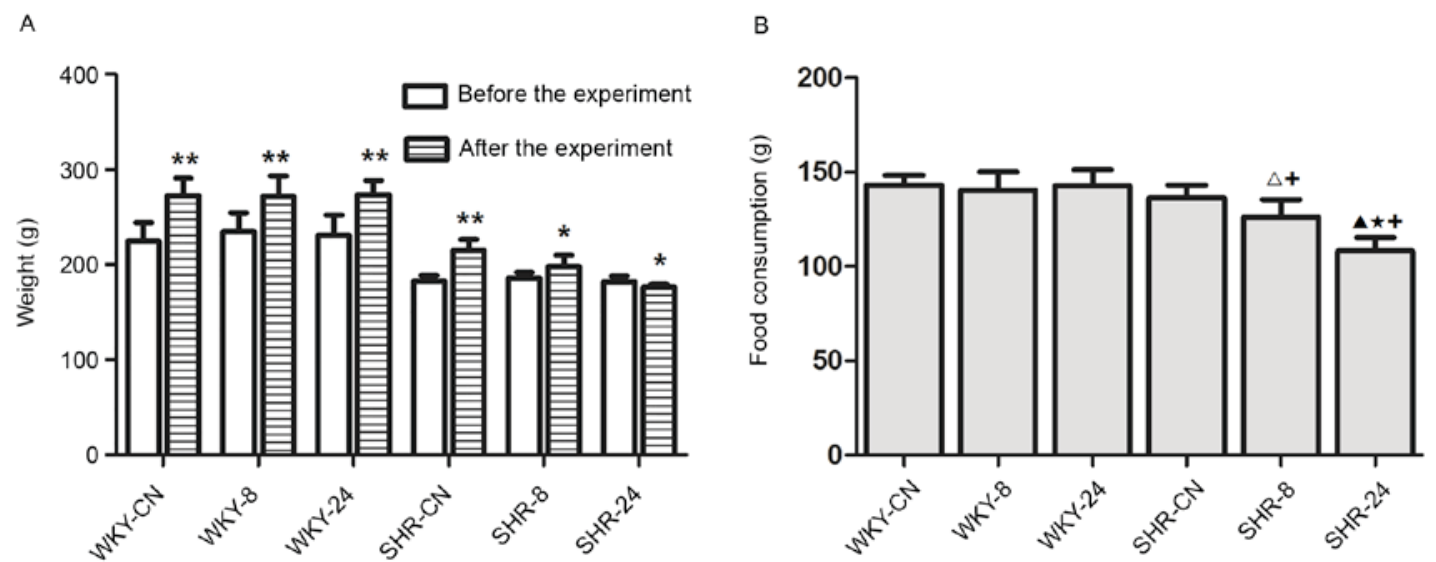

Figure 1. Effect of a hot and humid environment on rat (A) body weight and (B) food consumption. Data are presented as the mean \pm standard deviation ( $\mathrm{n}=8$ ). ${ }^{*} \mathrm{P}<0.05$ and ${ }^{* * *} \mathrm{P}<0.01$ vs. before the experiment. ${ }^{\wedge} \mathrm{P}<0.05$ and ${ }^{\boldsymbol{}} \mathrm{P}<0.01$ vs. SHR-CN; ${ }^{\star} \mathrm{P}<0.01$, SHR-24 vs. SHR-8; ${ }^{+} \mathrm{P}<0.01$ vs. WKY. WKY, Wistar-Kyoto rats; SHR, spontaneously hypertensive rats; $\mathrm{CN}$, control; -8 , heat exposure for $8 \mathrm{~h} ;-24$, heat exposure for $24 \mathrm{~h}$.

using an Amersham Imager 600 (GE Life Sciences, Chicaco, IL, USA).

Statistical analysis. Data were expressed as the mean \pm standard deviation. Statistical analyses were performed using SPSS version 17.0 software (SPSS, Inc., Chicago, IL, USA). Comparisons between the means of numerous samples were evaluated by analysis of ANOVA, and comparisons between the means of two samples were evaluated by Fisher's least significant difference t-test. $\mathrm{P}<0.05$ was considered to indicate a statistically significant difference.

\section{Results}

Weight and food consumption. Prior to heat exposure, all rats exhibited good appetite, agility and activity levels. Rats were restless in the evening. During thermal exposure, rats were tired and sleepy, and were observed to hide in the bedding material. As shown in Fig. 1A, the body weight of rats in each group at the end of the experiment was significantly increased compared with before the experiment $(\mathrm{P}<0.01$ for all WKY groups and SHR-CN; $\mathrm{P}<0.05$ for SHR-8), except for rats in the SHR-24 group, which exhibited significantly reduced body weight compared with before the experiment $(\mathrm{P}<0.05)$. There were no notable differences in food consumption among the WKY groups (Fig. 1B). Food consumption was significantly reduced in the SHR-8 and SHR-24 rats compared with SHR-CN $(\mathrm{P}<0.05$; Fig. 1B).

Blood pressure. Experimental results demonstrated that rat blood pressure was elevated in the high temperature and high humidity environment compared with the room temperature environment (Fig. 2). Following the experiment, systolic blood pressure was significantly increased in the WKY-24, SHR-8 and SHR-24 groups, as compared with before the experiment $(\mathrm{P}<0.01$; Fig. 2A). Diastolic blood pressure was also significantly increased in the WKY-24 $(\mathrm{P}<0.05)$, SHR-8 $(\mathrm{P}<0.01)$ and SHR-24 $(\mathrm{P}<0.01)$ groups after the experiment, as compared with before the experiment (Fig. 2B). As expected, systolic and diastolic blood pressure in SHRs was higher than in WKY rats.

Vasoreactivity. As shown in Fig. 3, the contractile responses of thoracic aortic vascular rings to NA in all groups increased as NA concentration increased. Vasoreactivity in WKY-8 was significantly increased compared with WKY-CN $(\mathrm{P}<0.01)$. Compared with the SHR-CN group, vasoreactivity in the SHR-8 group was also significantly increased $(\mathrm{P}<0.01)$. In both SHR and WKY groups, the increase in vasoreactivity in the 


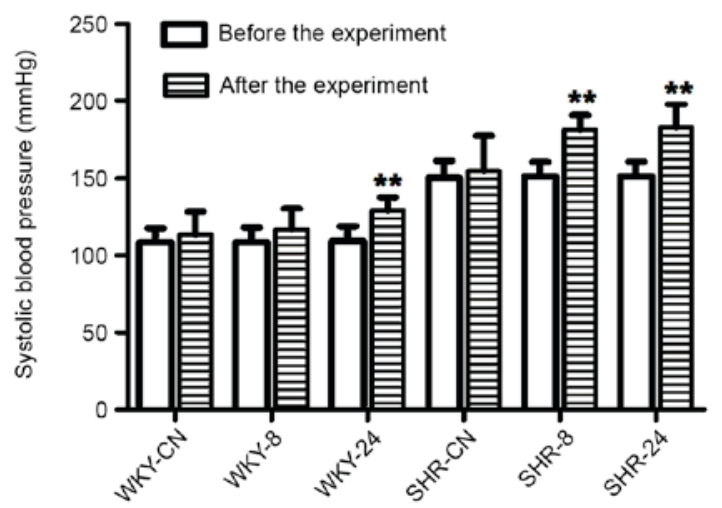

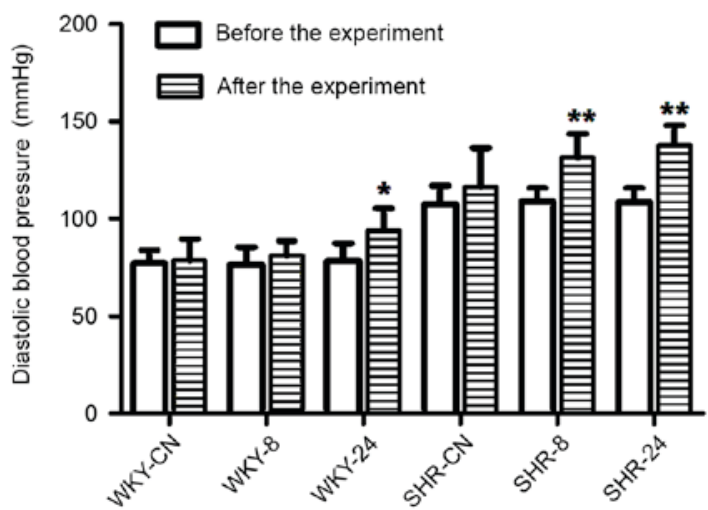

Figure 2. Effect of a hot and humid environment on (A) systolic and (B) diastolic blood pressure. Data are presented as the mean \pm standard deviation ( $\mathrm{n}=8$ ). ${ }^{*} \mathrm{P}<0.05$ and ${ }^{* *} \mathrm{P}<0.01$ vs. before the experiment. WKY, Wistar-Kyoto rats; SHR, spontaneously hypertensive rats; CN, control; -8 , heat exposure for 8 h; -24 , heat exposure for $24 \mathrm{~h}$.

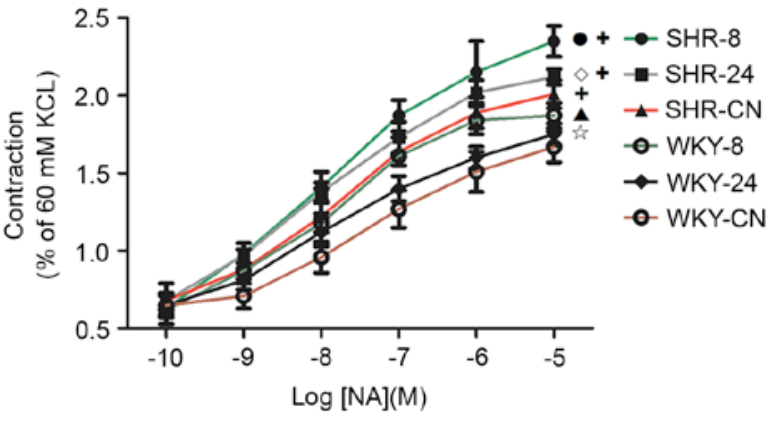

Figure 3. Effect of a hot and humid environment on vasoreactivity. Data are presented as the mean \pm standard deviation $(\mathrm{n}=8)$. ${ }^{\circ} \mathrm{P}<0.01, \mathrm{SHR}-8$ vs. SHR-CN; ${ }^{\circ} \mathrm{P}<0.05$, SHR-24 vs. SHR-8; ${ }^{\wedge} \mathrm{P}<0.01$, WKY-8 vs. WKY-CN; ${ }^{4} \mathrm{P}<0.05$, WKY-24 vs. WKY-8; ${ }^{+} \mathrm{P}<0.01$, SHR vs. WKY. WKY, Wistar-Kyoto rats; SHR, spontaneously hypertensive rats; $\mathrm{CN}$, control; -8 , heat exposure for $8 \mathrm{~h}$; -24 , heat exposure for $24 \mathrm{~h}$; NA, noradrenaline.

8 h-exposed group was significantly larger compared with the increase in the $24 \mathrm{~h}$-exposed group $(\mathrm{P}<0.05)$. Vasoreactivity in the SHR groups was significantly increased compared with the corresponding WKY groups $(\mathrm{P}<0.01)$.

Morphological observation. In the WKY-CN group, the intima of the aorta was smooth with a single layer of endothelial cells (Fig. 4A). In the WKY-8 group, endothelial cells detached and the endothelium was incomplete (Fig. 4B). In the WKY-24 group, endothelial cells were connected loosely, and the endothelium was partly missing (Fig. 4C), but the changes were less notable than in the WKY-8 group. In the SHR groups, the thoracic aorta was thicker and the arrangement of cells was slightly more disordered than in the WKY groups. In the SHR-CN group, the endothelial cells were mostly connected, and cells were arranged closely in the intima, medial and outer membranes (Fig. 4D). In the SHR-8 group, most of the endothelial cells were lost, the vascular intima was incomplete, some elastic fibers and collagen fibers were thicker, and cell distribution was disorderly (Fig. 4E). Similar changes were observed in the SHR-24 group (Fig. 4F), but these were more severe in the SHR-8 group.
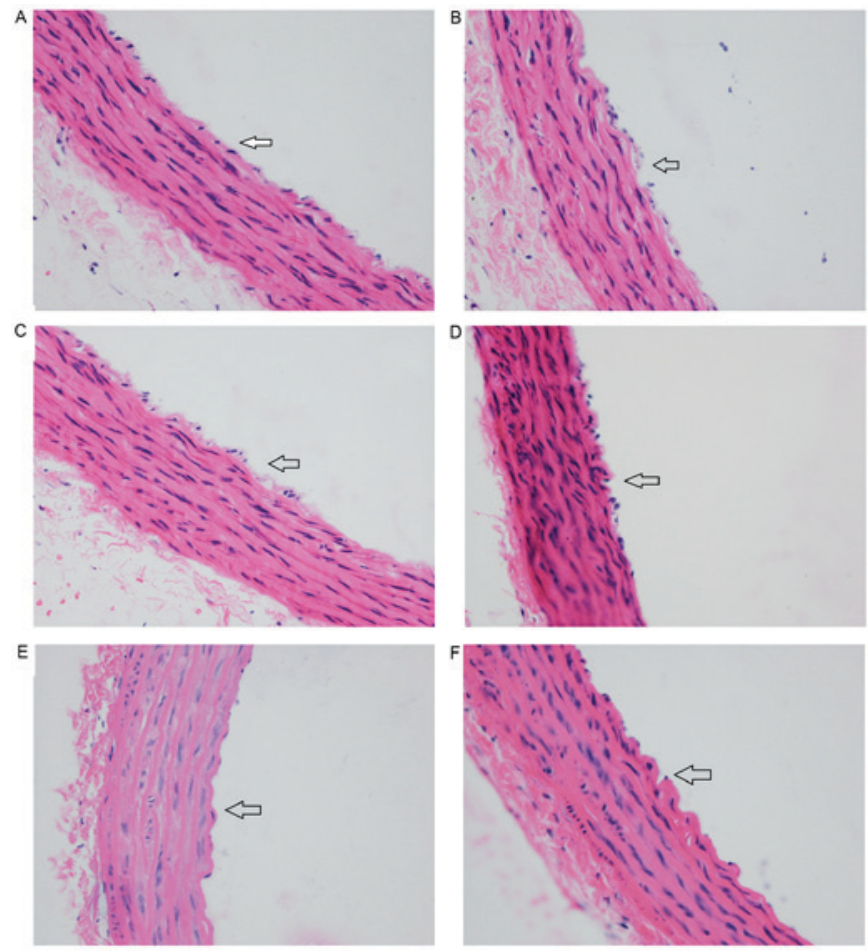

Figure 4. Effect of a hot and humid environment on vascular structures (A) WKY-CN group. (B) WKY-8 group. (C) WKY-24 group. (D) SHR-CN group. (E) SHR-8 group. (F) SHR-24 group. Arrows indicate the vascular intima in each image. Magnification, x400. WKY, Wistar-Kyoto rats; SHR, spontaneously hypertensive rats; $\mathrm{CN}$, control; -8 , heat exposure for $8 \mathrm{~h}$; -24 , heat exposure for $24 \mathrm{~h}$.

mRNA expression levels of caspase-3, Bcl-2 and Bax. In the hot and humid environment, the expression levels of apoptosis genes increased, and this increase was greater under discontinuous thermal stimulation than with continuous thermal stimulation (Fig. 5). mRNA expression levels of caspase-3 in WKY-8 and WKY-24 were significantly increased compared with WKY-CN ( $<<0.01$; Fig. 5A). Compared with the SHR-CN group, the mRNA expression level of Caspase-3 in the SHR-8 and SHR-24 groups was also significantly increased $(\mathrm{P}<0.01$ and $\mathrm{P}<0.05$, respectively). Expression levels of caspase- 3 in 


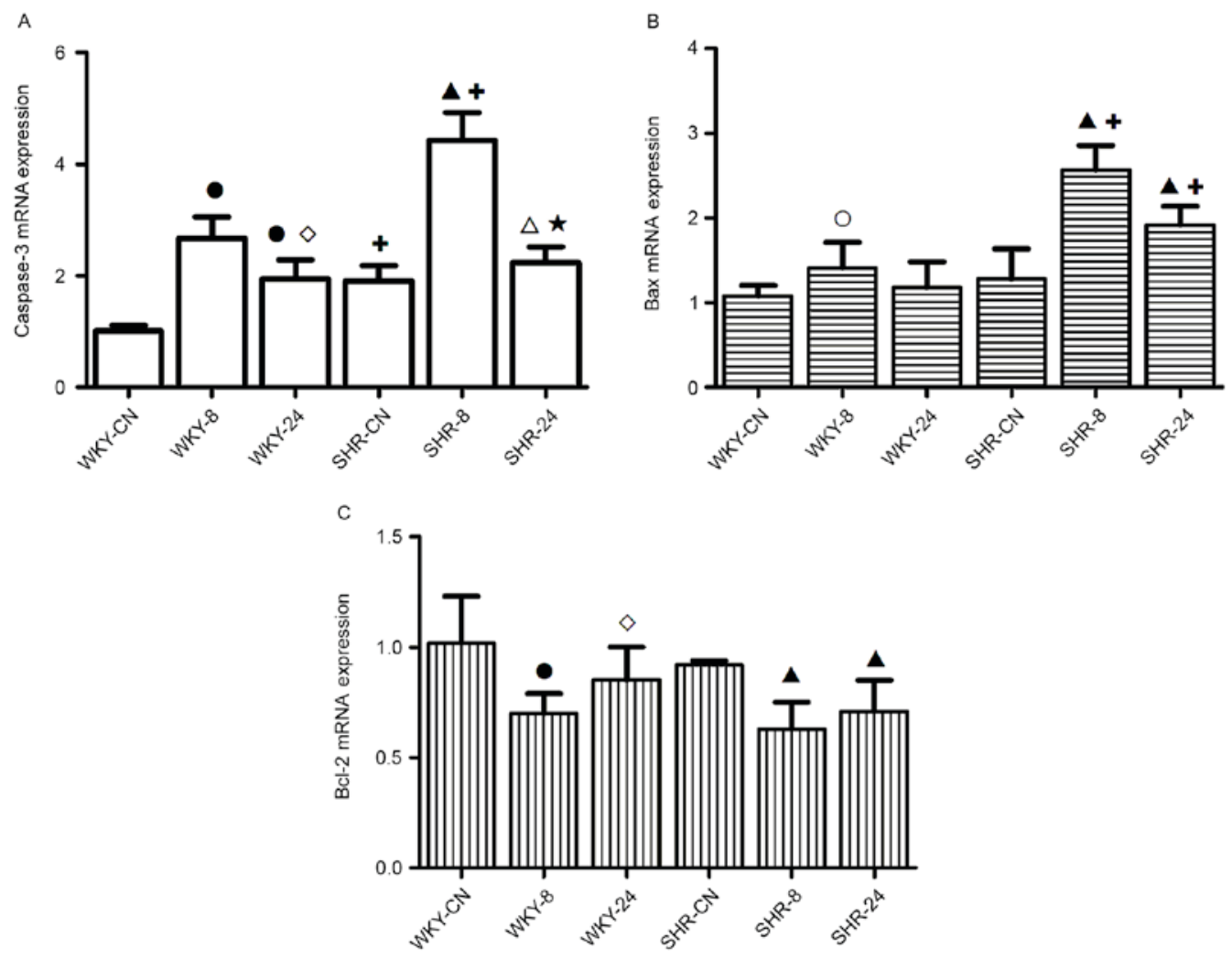

Figure 5. Effect of a hot and humid environment on the mRNA expression levels of (A) caspase-3, (B) Bax and (C) Bcl-2. Data are presented as the mean \pm standard deviation $(\mathrm{n}=8) .{ }^{\circ} \mathrm{P}<0.05$ and ${ }^{\bullet} \mathrm{P}<0.01$ vs. WKY-CN; ${ }^{\circ} \mathrm{P}<0.05$, WKY-24 vs. WKY-8; ${ }^{\wedge} \mathrm{P}<0.05$ and ${ }^{\wedge} \mathrm{P}<0.01$ vs. SHR-CN; ${ }^{\star} \mathrm{P}<0.01$, SHR-24 vs. SHR-8; ${ }^{+} \mathrm{P}<0.01$ vs. WKY. WKY, Wistar-Kyoto rats; SHR, spontaneously hypertensive rats; CN, control; -8, heat exposure for $8 \mathrm{~h}$; -24 , heat exposure for $24 \mathrm{~h}$; Bcl-2, B-cell lymphoma 2; Bax, Bcl-2-like protein 4.

the SHR-CN and SHR-8 groups were significantly increased compared with the corresponding WKY groups $(\mathrm{P}<0.01)$. Compared with the $8 \mathrm{~h}$-exposed group, the increased expression level of caspase- 3 in the 24 h-exposed group was weaker in both WKY and SHR groups $(\mathrm{P}<0.05, \mathrm{P}<0.01$ respectively; Fig. 5A).

Compared with WKY-CN, the Bax apoptosis gene was significantly upregulated in WKY-8 ( $\mathrm{P}<0.05$; Fig. 5B). Compared with the SHR-CN group, the expression levels of Bax in the SHR-8 and SHR-24 groups were significantly increased $(\mathrm{P}<0.01)$. In the high temperature and high humidity environment, the expression levels of Bax in the SHR groups were significantly increased compared with the corresponding WKY groups $(\mathrm{P}<0.01)$.

Under the high temperature and high humidity conditions, the expression level of Bcl-2 in the WKY-8 group and SHR groups was significantly decreased, as compared with the respective controls $(\mathrm{P}<0.01$; Fig. $5 \mathrm{C})$. Compared with the WKY-8 group, the expression level of Bcl-2 in the WKY-24 group was significantly increased $(\mathrm{P}<0.05$; Fig. 5C).

Protein expression levels of caspase-3, Bcl-2 and Bax. Western blotting (Fig. 6A) indicated that the Caspase-3 protein level increased in the SHR-8 group when compared with the SHR-CN group (Fig. 6B); the protein levels of caspase-3 in the SHR-24 was significantly decreased compared with the SHR-8 group $(\mathrm{P}<0.01$; Fig. $6 \mathrm{~B})$, there were no notable differences among the WKY groups, however, the caspase-3 level was elevated in both SHR-8 and SHR-24 groups than in WKY-8 and WKY-24 groups $(\mathrm{P}<0.01, \mathrm{P}<0.05$; Fig. 6B). In the high temperature and humidity environment, protein expression levels of Bax were significantly increased, as compared with the control, respectively $(\mathrm{P}<0.01$; Fig. $6 \mathrm{C}$ ), whereas $\mathrm{Bcl}-2$ protein expression levels were significantly decreased compared with the control in both types of rat $(\mathrm{P}<0.01$; Fig. 6D), and compared with the SHR-8 group, the protein level of Bcl-2 in the SHR-24 group was significantly decreased, the decreased level of Bcl-2 in SHR-8 was weaker than in the WKY-8 group $(\mathrm{P}<0.01$; Fig. 6D). These results were broadly consistent with the mRNA analysis.

\section{Discussion}

The present study investigated the effects of a hot and humid environment on thoracic aorta damage in SHR. The results of the present study revealed increased expression of Caspase- 3 and Bax, and reduced expression of Bcl-2 in a hot and humid environment. Morphological observation of the thoracic aorta and detection of vasoreactivity also indicated that the structure and function of blood vessels was altered by the hot and humid environment. Adverse effects on the rats' weight, diet and blood pressure were also observed. According to these results, thoracic aorta damage was more severe when rats were in a discontinuous thermal environment, as compared with a continuous one.

In recent decades, the burden of cardiovascular disease has increased to become a major public health problem requiring urgent prevention and treatment strategies (16). 


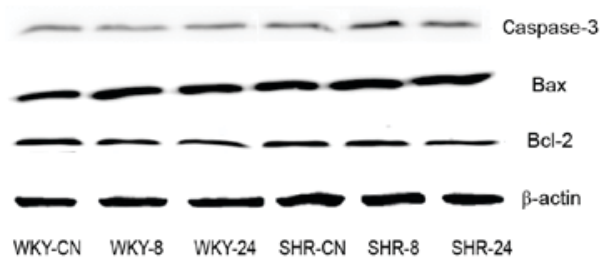

C

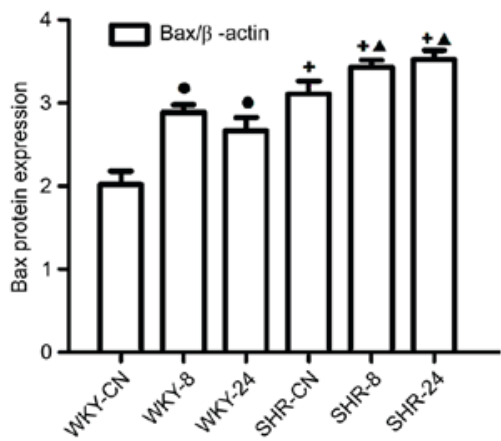

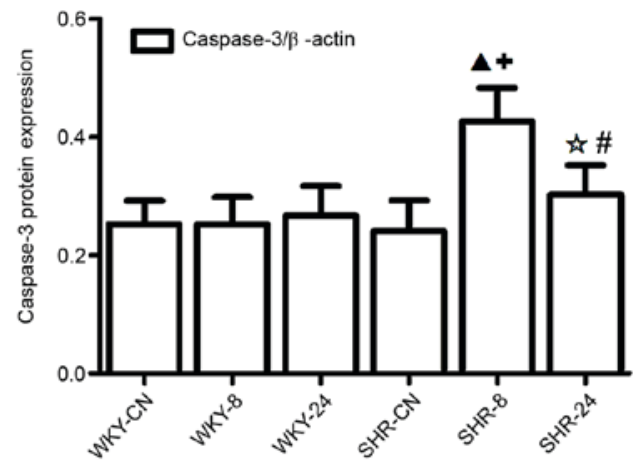

D

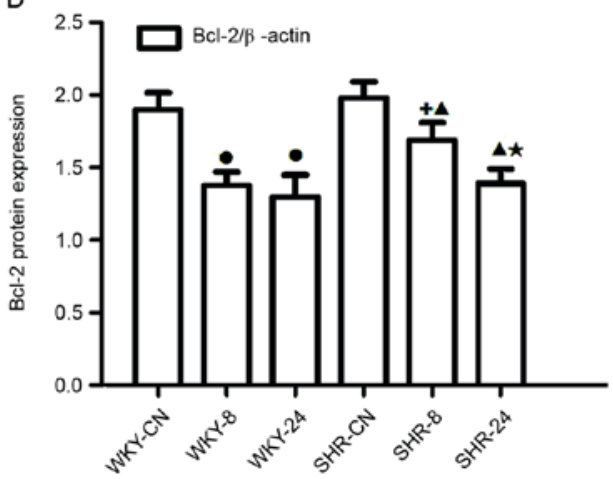

Figure 6. Effect of a hot and humid environment on the expression of apoptotic proteins. (A) Western blot analysis was performed to quantify protein expression levels of (B) caspase-3, (C) Bax and (D) Bcl-2. Data are presented as the mean \pm standard deviation $(\mathrm{n}=8)$. ${ }^{\circ}<<0.01$ vs. WKY-CN; ${ }^{\Delta} \mathrm{P}<0.01$ vs. SHR-CN; ${ }^{\star} \mathrm{P}<0.05$ and ${ }^{\star} \mathrm{P}<0.01$, SHR-24 vs. SHR-8; ${ }^{*} \mathrm{P}<0.05$ and ${ }^{+} \mathrm{P}<0.01$ vs. WKY. WKY, Wistar-Kyoto rats; SHR, spontaneously hypertensive rats; CN, control; -8 , heat exposure for $8 \mathrm{~h}$; -24, heat exposure for $24 \mathrm{~h}$; Bcl-2, B-cell lymphoma 2; Bax, Bcl-2-like protein 4.

The effect of a continuous high temperature environment on health has been studied both in China and abroad (17). High temperature affects the body's blood dynamics and endocrine system (18), the amount of blood near the surface of the body is increased, and the blood supplied to the heart is relatively reduced under high temperature conditions, leading to cerebral ischemia and hypoxia (19). Meanwhile, the human body sweats under high temperature, which results in loss of water and thickening of the blood, which are dangerous factors in the occurrence of hypertension disease (20). However, the effect of high temperature environment on hypertension remains unclear.

In the present study, SHRs were used as the disease model. The effect of a high temperature and humid environment was investigated in these rats by measuring indices associated with apoptosis, in order to investigate the corresponding changes in blood vessels in hypertensive rats and the underlying pathophysiological mechanisms. Along with high temperature (5), high humidity also affects blood dynamics by affecting heat dissipation, therefore, rats were exposed to high temperature and high humidity conditions together. The results revealed that food intake was slightly reduced in the hot and humid environment in SHRs. The activity of rats was reduced during the day. The SHR-24 group exhibited a decrease in body weight over the course of the experiment. Furthermore, blood pressure was increased in both WKY rats and SHRs in the 24-h heat exposure group, however, 8-h heat exposure only increased blood pressure in the SHRs, no elevation of blood 4383-4390pressure was observed in WKY rats after 8-h exposure. This indicated that the SHRs were more sensitive to a thermal environment compared with WKY rats.

Vasoreactivity is one of the most basic and direct indices used to assess artery blood vessel function (21). Enhanced contractive function is the primary characteristic of a damaged blood vessel (22). In the present study, vasoreactivity of the thoracic aorta indicated that contractive function was enhanced in the hot and humid environment. Morphological observation of the thoracic aorta revealed that the structure was altered by exposure to a hot and humid environment. The most marked difference was the lack of endothelium. Endothelium-dependent vasodilatation is important in regulating the function of the aorta (23), therefore the loss of the endothelium may affect contractive function.

Apoptosis describes the programmed death of a cell as part of its natural growth and development (24). Apoptosis has a key regulatory function in the body, and can be induced by stress, such as free radicals, hypoxia, blood deficiency or high temperature (25). Caspase-3 is thought to be an important apoptosis indicator, its activation results in an irreversible stage of apoptosis (26). In the process of cell apoptosis, Bcl-2 and Bax have critical functions, increased Bax promotes cell apoptosis, whereas increased Bcl-2 inhibits cell apoptosis (27). The present study demonstrated a hot and humid environment elevates the expression of caspase- 3 and $\mathrm{Bax}$, whereas $\mathrm{Bcl}-2$ was reduced, the elevation of caspase- 3 and Bax were more obvious in SHR rats while 
the downregulation of Bcl-2 was more stronger in WKY rats. These results suggested that cell apoptosis was induced by the hot and humid environment. The loss of the endothelium may have been associated with the increased number of apoptotic cells, thus resulting in an altered organizational structure of blood vessels. This may also affect the function of blood vessels. The SHR rats were more sensitive to the hot and humid environment.

Heat acclimation, a conserved phenotypic adaptive response to the prolonged transfer to a higher ambient temperature, confers protection against acute heat stress and delays thermal injury (28). The heat acclimation process may strengthen the body to heat tolerance and make blood vessels dilate (29). High temperature and humidity environments are a type of stimulation. When rats are housed in this environment for a long time, the body may gradually adapt to this type of stimulation, and a variety of disorders in the body will also move gradually toward the normal value (30). However, it is difficult to restore to the normal condition. Therefore, prior to the end of the present experiment, rats (WKY-24 and SHR-24) in the high temperature and humidity environment for 7 days had begun to enter the heat acclimation process. However, due to the discontinuous cold and hot stimulation, WKY-8 and SHR- 8 rats remained in a state of stress and therefore found it difficult to enter the heat acclimation process. This might be the reason why $8 \mathrm{~h}$-exposure induced more significant damage to the blood vessel. Therefore, the present study concluded that intermittent heat stress was more harmful than the continuous heat stress to blood vessels.

In conclusion, apoptosis in the thoracic aorta was increased under hot and humid conditions, this may be related to the altered organizational structure and increased contractive function of thoracic aorta. The disturbance of structure and function on thoracic aorta was more notable in rats with spontaneous hypertension under heat stress. The blood vessel was more sensitive to intermittent heat stress than the continuous heat stress. Besides, increased apoptosis may also have occurred elsewhere in the body, affecting the rats' body weight, which requires further experiments to confirm this.

\section{Acknowledgements}

This study was supported by the National Natural Science Foundation of China (grant no. 81560052) and the Ningxia Natural Science Foundation Key Project (grant nos. NZ13055 and NZ16065) and West China Top Class Discipline Project in Basic Medical Science, Ningxia Medical University (grant no. 2017016).

\section{References}

1. Hausfater P, Doumenc B, Chopin S, Le Manach Y, Santin A, Dautheville S, Patzak A, Hericord P, Mégarbane B, Andronikof $\mathrm{M}$, et al: Elevation of cardiactroponin I during non-exertional heat-related illnesses in the contextof a heatwave. Crit Care 14: R99, 2010.

2. Li G, Zhou M, Cai Y, Zhang Y and Pan X: Does temperature enhance acute mortality effects of ambient particle pollution in Tianjin City, China. Sci Total Environ 409: 1811-1817, 2011.

3. Yibin JI, Liping P and Jun W: Assessment of thermal comfort for aircraft cabin environment. J Safety Environment 15: 306-309, 2015.
4. Shi YJ, Yu JR, Cen XN, Zhu Q and Ren HY: Influence of HSP70 on combined method of hyperthermia and immunologic effector cells to treat cancer. Beijing Da Xue Xue Bao 37: 175-178, 2005 (In Chinese).

5. Pathapati RM, Rajesh Kumar M, Chirra BR, Buchineni M, Sujith TR, Devaraju SR and Naidu MUR: Acute effects of two angiotensin receptor blockers on vascular hemodynamics, arterial stiffness and oxidative stress in patients with mild to moderate hypertension: An open label parallel group study. ISRN Vascular Med 2013: 5, 2013.

6. Manning EP and Wilson B: Dehydration in extreme temperatures while conducting stability and support operations in a combat zone. Mil Med 172: 972-976, 2007.

7. John K, Rösner I, Keilholz U, Gauler T, Bantel H and Grünwald V: Baseline caspase activity predicts progression free survival of temsirolimus-treated head neck cancer patients. Eur J Cancer 51: 1596-1602, 2015

8. Liu Y, Zheng Q, Wu H, Guo X, Li J and Hao S: The effects of rapamycin on expression ratio of $\mathrm{Bax} / \mathrm{Bcl}-2$ and the expression of activated caspace-3 in different types of tumor cells. Tumor 33: 138-145, 2013.

9. Anvekar RA, Asciolla JJ, Missert DJ and Chipuk JE: Born to be alive: A role for the BCL-2 family in melanoma tumor cell survival, apoptosis, and treatmen. Front Oncol 1: pii:00034, 2011.

10. Zhang SD, Shan L, Li W, Li HL and Zhang WD: Isochamaejasmin induces apoptosis in leukemia cells through inhibiting Bcl-2 family proteins. Chin J Nat Med 13: 660-666, 2015.

11. Li GH, Katakura M, Maruyama M, Enhkjargal B, Matsuzaki K, Hashimoto $\mathrm{M}$ and Shido O: Changes of noradrenaline-induced contractility and gene expression in aorta of rats acclimated to heat in two different modes. Eur J Appl Physiol 104: 29-40, 2008.

12. Kim Y, Kim J, Kim M, Baek W and Kim I: Effect of heat shock on the vascular contractility in isolated rat aorta. J Pharmacol Toxicol Methods 42: 171-174, 1999.

13. Morimoto T, Miki K, Nose H, Itoh T and Yamada S: Changes in vascular compliance during hyperthermia. J Thermal Biol 9: 149-151, 1984.

14. Crandall CG and González-Alonso J: Cardiovascular function in the heat-stressed human. Acta Physiol (Oxf) 199: 407-423, 2010.

15. Guanghua LI, Zhao N, Yang M, Zhao Z, Luo Y and Osamu S: Effects of heat exposure during fixed time on thoracic aorta contractility in rats. Academ J Second Military Med Univ 34: 291-294, 2013.

16. Liu X, Cui Y, Yang Y and Li L: Study on neuroendocrine mechanism of occurrence of cerebral infarction in hypertension rats induced by soaring temperature. Progress Modern Biomedicine 8: 1428-1431, 2011.

17. Brazaitis M and Skurvydas A: Heat acclimation does not reduce the impact of hyperthermia on central fatigue. Eur J Appl Physiol 109: 771-778, 2010.

18. Haiyan Y, Liu Y, Wuxing Z and Daoyi L: Influence of outdoor temperature on the indoor environment and thermal adaptation in Chinese residential buildings during the heating season. Energy Buildings 116: 133-140, 2016.

19. Maglara AA, Vasilaki A, Jackson MJ and McArdle A: Damage to developing mouse skeletal muscle myotubes in culture: Protective effect of heat shock proteins. J Physiol 548: 837-846, 2003.

20. Zhao Z, Yang M, Zhao N, Liu H, Dong J and Li G: Influence of Lycium barbarum polysaccharides on thoracic aortic vascular reactivity and free radical metabolism at high temperature in exhaustive exercise rats. J Ningxia Med Univ 35: 481-484, 2013.

21. Laurent S, Cockcroft J, Van Bortel L, Boutouyrie P, Giannattasio C, Hayoz D, Pannier B, Vlachopoulos C, Wilkinson I and Struijker-Boudier H; European Network for Non-invasive Investigation of Large Arteries: Expert consensus document on arterial stiffness: Methodological issues and clinical applications. Eur Heart J 27: 2588-2605, 2006.

22. Swierblewska E, Hering D, Kara T, Kunicka K, Kruszewski P, Bieniaszewski L, Boutouyrie P, Somers VK and Narkiewicz K: An independent relationship between muscle sympathetic nerve activity and pulse wave velocity in normal humans. J Hypertens 28: 979-984, 2010.

23. Zhao Z, Luo Y, Li G, Zhu L, Wang Y and Zhang X: Thoracic aorta vasoreactivity in rats under exhaustive exercise: Effects of Lycium barbarum polysaccharides supplementation. J Int Soc Sports Nutr 10: 47, 2013.

24. Salvesen GS and Ashkenazi A: Snapshot: Caspases. Cell 147: 476.e1, 2011. 
25. Jonestone RW, Ruefli AA and Lowe SW: Apoptosis: A link between cancer genetics and chemotherapy. Cell 108: 153-164, 2002.

26. Wang LI, Liu F, Luo Y, Zhu L and Li G: Effect of acute heat stress on adrenocorticotropic hormone, cortisol, interleukin-2, interleukin-12 and apoptosis gene expression in rats. Biomed Rep 3: 425-429, 2015.

27. Li Z, Zhao J, Li Q, Yang W, Song Q, Li W and Liu J: KLF4 promotes hydrogen-peroxide-induced apoptosis of chronic myeloid leukemia cells involving the bcl-2/bax pathway. Cell Stress Chaperones 15: 905-912, 2010.
28. Horowitz M: From molecular and cellular to integrative heat defense during exposure to chronic heat. Comp Biochem Physiol A Mol Integr Physiol 131: 475-483, 2002.

29. Horowitz M, Eli-Berchoer L, Wapinski I, Friedman N and Kodesh E: Stress-related genomic responses during the course of heat acclimation and its association with ischemic-reperfusion cross-tolerance. J Appl Physiol (1985) 97: 1496-1507, 2004.

30. Schwimmer H, Gerstberger R and Horowitz M: Heat acclimation affects the neuromodulatory role of AngII and nitric oxide during combined heat and hypohydration stress. Brain Res Mol Brain Res 130: 95-108, 2004 